\title{
Two Models of Traditionalism in China at the Beginning of the XX Century: Kang Yu-Wei and Cheung Bin-ling
}

\author{
Dmitry E. Martynov ${ }^{1}$ \\ ${ }^{1}$ Kazan (Volga Region) Federal University, Kazan, Russia \\ Correspondence: Dmitry Evgenyevich Martynov, Kazan (Volga Region) Federal University, Kremlyovskaya \\ street, 18, Kazan 420008, Russia. E-mail: dmitrymartynov80@mail.ru
}

\author{
Received: April 14, 2015 Accepted: April 20, 2015 Online Published: April 27, 2015 \\ doi:10.5539/jsd.v8n4p211 URL: http://dx.doi.org/10.5539/jsd.v8n4p211
}

\begin{abstract}
The urgency of a studied problem consists in need of research of traditionalist roots for modern Chinese ideology. At its sources two radical thinkers of the beginning of the XX century - Caen Yu-vey and Cheung Bin-ling are put. The article is devoted to comparative comparison of models of the traditionalism offered by radical Chinese thinkers of China both of whom passed the way from political reformism to conservatism. The leading method to research of this problem is the comparative method applied in a wide historical context of so-called "transitive period". In the article it is shown that at the beginning of the XX century there was a radical erosion of a traditional picture of the world which demanded some kind of radical reorganization of a universe in public consciousness. Both Kahn Yu-wei and Cheung Bin-ling were based on humanitarian potential of the Chinese civilization, but offered absolutely different ways of realization of the ideal. The materials of the article can be useful to political scientists, sociologists and the historians who are taking up the problems of evolution of public consciousness and formation of public consciousness.
\end{abstract}

Keywords: utopia, socialism, nationalism, Kang Yu-wei, Cheung Bin-ling

\section{Introduction}

The era prior to the beginning of Xinhai revolution (1911) shows very complicated and inconsistent processes not only in sociopolitical, but also the intellectual sphere. Cheung Hao designated the period of 1890-1911 as "transitive" in which the Chinese intellectual class appeared to be torn into two camps - reformists and revolutionaries, and this division at the beginning concerned only the theory and methods of jump-start the country, without mentioning the bases of a spiritual development (Chang, 1987).

The Chinese civilization developed peculiar forms of perception of reality, the system of universal concepts and categories which formed the world model, called by Cheung Hao an orientational symbolism (Chang, 1987). The function of the Chinese traditional thought is coherence and order maintenance between structural parts of the universe allowing not only to realize the personality in categories of space and time, but also to establish universal concepts of meaning of the life of the individual and the purpose of social development.

The world picture, existing in China since neolith, provided division of everything and everybody on a dichotomy "the center - the periphery", "external - internal" and did not separate the natural and social environment. By the middle of the XIX century it began to give in under the influence of two external factors: violence caused by armies of the western countries in trading wars of 1840-1860 and also destruction of traditional moral foundations under the influence of mass opium trade. A new picture of the world found reflection in treatises of Wei Yuan very popular at that time (魏源, 1794-1856) who in the "Description of the overseas countries" acquainted readers not only with household details but also, for example, with Great French revolution (that is why this book enjoyed wide popularity in Japan and even became one of ideological justifications of revolution of Meiji). It is worth noticing that Wei Yuan did not mention deep bases of traditional society, moreover he considered sincerely that the Chinese civilization is much higher than any strange inventions of "long-nosed barbarians". However the quantity of the facts grew, there were new translations of the western missionaries which provoked absolutely specific objective: how to combine the traditional and "borrowed" pictures of the world?

Cheung Hao mentioned the Sichuan scientist Sung Yu-gen (宋育仁, 1857-1932), who had tried to combine the 
Universe of Copernicus with cosmological symbolism, dualism of Yin-Jang and the system of five initial elements. It is characteristic that Sun Yu-gen came to a conclusion about inevitable demolition of a traditional social and state order as it is inseparably linked with cosmology. Moreover, the ethical Universalizm of Christianity contradicts to an ethical particularism of the Chinese system and cannot compete with it (Chang, 1987).

On the threshold of reforms of the summer 1898 among a number of representatives of the Chinese elite there had appeared the ideas of parliamentarism. For example, Zheng Guan-ying (鄭觀應, 1842-1922), being an outstanding person of the regime and a powerful businessman, hardly mentions the sphere of sacral in his theoretical works though the doctrine about symbols and numbers takes a considerable place in his works. Thus Chen Zhi (陳熾) absolutely departed from traditional cosmological views and for the first time in the Chinese thought put forward monarchy apologia from a position of national solidarity between ruling circles and operated. Moreover, he considered democracy (Ming Chuan 民權) the unique means from mutinies against legitimate authority and chaos establishment in the country.

\section{Methodological Framework}

The use of a comparative-historical method within a functional approach is the only possible in the specific historical context. In other words, we consider ideological complexes as expression of historical consciousness of their creators, naturally, incorporated in a certain model of reality. This model can be stationary - for the European thinkers of the XIX century - or non-stationary, as in China of the transitive period. Definite calls of an era can get various answers, and not necessarily being reduced to specific personal features, it can also be generated by social environment, a social standing etc. The figures of Kang Yu-wei and Cheung Bin-ling are chosen for comparison as the most antagonist Chinese thinkers of the era.

\section{Results}

\subsection{Kang Yu-wei as a Thinker of the Transitive Period: The Use of a Tradition for Justification of Innovations}

The western influence was the most powerful factor in intellectual life of China of the "transitive period". By 1890th missionary stations had started to function in internal regions of the country and to make direct impact on wide layers of Chinese intellectuals (Martynov, 2008). The specific feature of this process was that the representatives of the Chinese intellectuals met the western civilization rather late, having received a full cycle of traditional Confucian education: Kang Yu-wei (1858-1927) visited Hong Kong for the first time at the age of 22. It led to the fact that "cultural identity" prevailed over Chinese intellectuals of the transitive period (the term of Levenson). On the other hand, Levenson considered following the tradition and continuous underlining of its priority and as a result of some kind of psychotherapy, the necessity to cure the emotional wounds got from experience of communication of China with the western countries (Levenson, 1968). The complex of traditional texts and ideas was self-sufficing intellectual force in itself, however the Confucian tradition was far from scholasticism, and though the same problem was discussed from century to century the tradition still was not perceived as dead weight. Paradoxically, but Confucian scientific community which in the XIX century vividly discussed the problems formulated 1700years before, is closer to the Russian concept "sobornost" as was at the same time both environment and the mechanism, allowing to consider structure-forming issues and problems in time and at the same time out of time. Cheung Hao calls this phenomenon internal dialogues.

According to the definition of Liang Qi-chao, - "Kang Yu-wei is an educated and progressive person but at the same time - the inveterate conservative who has been extremely adhered to old times. He loves ancient stones and bronze very much, ancient literary monuments and various ancient utensils. It is devoted to old friends and is kind to fellow- villagers. Reflecting on destinies of China, he goes on telling about preservation of national culture (Guo Cui). As a scientist, the teacher got into a history root. He moved from creation of political societies to spirituality. I know that having studied the western sciences a little, the teacher began to hold old times even stronger. It is explained by the fact that he wishes China good luck" (Kang Yu-wei, 2007). The weird combination of conservatism and modernism in the doctrine of Kang Yu-wei was explained by the traditional base of his outlook - having endured an enlightenment at the age of 21, Kang Yu-wei considered himself a modern analogy of Confucius who was charged by the Heaven to rescue China ( Hsiao, 1975). The total failure of political plans, disorder of China and all traditional civilization could not but influence the thinker. During his travel across Italy in 1904, having visited ruins of Pompeii, Kang Yu-wei wrote: "When Pompeii was destroyed, its destruction was regarded as an unusual and great calamity. But later, after excavation work had been done, it became a marvelous archaeological spectacle. But for the volcanic eruption, we would not now see ruins of] of this ancient city of the Romans. [Similarly,] but for the First Emperor of Qin [whom historians have condemned as an evil tyrant], we would not have today the Great Wall. In our world, gains and losses complement each other, 
despite their polarity. Hence one who discourses on the Dao cannot dispense with notions of] of yin and yang ... Persons, who see only one side, see very little; they are not qualified to discuss the Dao" (Hsiao, 1975).

Disruption of traditional cosmological views was closely connected with the loss of traditional ideological reference points therefore the judgment of political crisis and destruction of the bases of a traditional Chinese civilization turned literally disastrous for thinkers. For centuries of its development the Chinese civilization had worked out peculiar forms of perception of reality, the system of universal concepts and categories which formed the world model, that one which Cheung Hao called orientational symbolism. However the function of the Chinese traditional model of reality is coherence and order maintenance between structural parts of the universe allowing not only to realize the personality in categories of space and time, but to establish also universal concepts of meaning of the life of an individual and the purpose of social development. Thus, the Chinese intellectuals in the 1890th became the victims of a cognitive discord, and they had to recreate not only concepts of sociopolitical development, but also the ideas of a universe and the purposes of human life.

It is natural that the scales of this crisis and even its existence were realized by different people in very different measure. The following extract from the "Autobiography" of Kan Yu-wei written in 1895 may serve an example: "When I was in the capital, a certain noble person asked: "Will the reigning dynasty stay one hundred years more?" I answered: "Disarsters are being evidently developed, what is the use of words about one hundred years?" The official decided that I had told nonsense" (Martynov, 2010). In other words, some representatives of elite had a feeling of vague fear, others were sharply worried, and still others, including Kang Yu-wei and his numerous pupils, intended to react, but even this reaction had an unusual look for us: this desire to recreate space once again, having built a new comprehensive view of the world, but the look already considering a great number of new phenomena which should be comprehended and included in the system of space correlations. Thus, the Chinese thinkers of that period faced an existential call, and it is a very serious argument for the concept about utopia and an utopian answer to the call of time and the era became the property of the Chinese civilization only during this period.

The canon Da sue ("The great doctrine") got a special value in the XIX century among Confucian initial texts , it had been considered a kind of highest textbook for all adult people since Song dynasty. In the conditions of "reformation" of the whole universe the special role in consciousness of the intellectuals was occupied by revival of a practical ideal of the moral personality. Respectively Da sue was considered a peculiar "key" which will allow the issues of Khan and Song (neo-Confucian) doctrines to merge. The issues of $D a$ sue have two measurements - internal and external. Internal measurement opens a personalistic perspective, external oneinstitutional, concentrated on a question of mechanism formation of the outside world regulation. There is a tragic paradox: the main values described in Da sue, contradicted the problems of the external direction. The adherents of the external direction, having got acquainted with the living conditions in the imperialistic West, did not separate a political order from wealth and the power, but at the same time could not but realize that Confucian values are absolutely distinctly opposed to benefit, wealth and the power. The appeal to heritage of the Chinese thinkers of the XVII century - Yan Yuan (1635-1704) and Juan Tsung si (1610-1695) was a way out in this situation. Huan Tsung-si recognized as legitimate both hereditary, and not hereditary monarchy as he considered "Heavenly Empire as the master, and the governor as the guest", and not vice versa. Among the contemporaries of Kang Yu-wei Chen Qiu was a bright representative of this direction (1851-1903), he basing upon very similar logic considered wealth and power as initial Confucian values. Respectively, he was charmed with the "utilitarian" direction of Confucian thought and considered the categories "wealth" of great value in the reformatory program. Wishing to see the world holistic in the future, he assumed specific principalities and extensive patriarchal families its main structural units. Sung Shu (1862-1910) who tried in his works to place wealth and power in the main hierarchy of Confucian values was another bright representative of this direction. Comparison of these categories in Confucian and legists views was an innovation. According to his opinion, "legist concentrated on increase of political power, and Confucians concentrated on moral responsibility in order not to allow aggression and to protect the weak". It allowed him to reconcile incompatible systems of values (Chang, 1987).

The perspective of the Chang's doctrine lay in the similar course: the representatives of this direction aimed at interpretation of a Confucian canon in the utilitarian purposes, thus trying to develop the mechanism of creation of the perfect state. It is natural that the chronicle Chung qiu, Gugnjani Zhuang with the subcomment of Hye Sue etc. was the main text for this direction. Apparently, it is necessary to admit, though quite indirrectly, Christian influence on the activity of this school: the tendency to transform Confucius into the divine figure, the first prophet on Earth and the reformer, even greater than Zhou-gong, was led to a logic end by Kang Yu-wei. At the same time, this theory was quite far from all the prototypes. Its main peculiarity was an absolutely new view on 
history which was considered as a directed, but impersonal process from chaos to the general order, passing by the phases of changes in society and ritual. Thus, within the same direction we see mystical-mythological line alongside with a claim for revival of original Confucianism of an antiquity.

\subsection{Radicalism of Cheung Bin-ling. from Buddhism to Revolutionary Conservatism}

Cheung Bin-ling (1869-1936) was one of the most paradoxical and inconsistent Chinese thinkers. Being considered alongside with Sun Yatsen the main ideologist of revolutionary movement in China, he was one of the most consecutive Chinese conservatives. Nationalism was the kernel of his political and legal views. If Kang Yu-wei considered nationalism in the cultural and social plan a natural process of perception of the achievements of the European civilization at preservation of national specifics, Cheung Bin-ling interpreted nationalism in the most literal and radical sense. Nationalism had led him to a complete negation of achievements of the western social sciences and negligence to them was even seen in his earliest works of the 1890th. In the 1920th he created the theory of difference between a "national" and "western" science and consistently emphasized the priority of the development of national humanities and auxiliary character of the western sciences which are of value only in the field of technical development (Kalyuzhnaya, 1995).

The originality of Cheung Bin-ling's revolutionary views was defined by his ideas of greater ease of a revolution in comparison with gradual reforms (which Kang Yu-wei stood up for). Revolution implementation according to Cheung Bin-ling needs unanimity of the people at large while reforms need political mind of a single person. Revolution is provided with national support by definition, thus unanimity of the people is also a political mind. The appeal to revolutionary creativity of the people allowed Cheung Bin-ling not to concretize the content of social transformations. He did not define the concepts "republic", "political revolution" and "social revolution" as well. By 1907 «racial revolution» had been added to those concepts, but again without disclosure of its contents (Laitinen, 1990).

In a political sense Cheung Bin-ling was an apologist of "glory revival" (Huang Fu) of the Chinese nation. Admiring political and economic institutions of the ancient China and neglecting western social science, Cheung Bin-ling could follow only archaic samples in designing a model of a future state system of China. In particular, he stood up for the revival of the "well-fields" system, examination system and traditional criminal law.

What concerns the utopian project of Cheung Bin-ling published in 1907 in Sung Yat-sen's magazine «Ming bao» (民報), issued in Japan, it is quite obvious. This project was expressed in a small article (22 pages of the Chinese text) “About five disappearances" (Uu lung 五無論) in which the space future of mankind submitted in certain respect was described much more considerably than in works of Kang Yu-wei and Tan Si-tung (1865-1898) taken together.

In historiography the utopia of Cheung Bin-ling was estimated differently: so, Kendzi Simada thought that it was"a typical example of romantic irony", while Cheung Zhao -ee called the essay "anarchism promotion". Actually, everything is slightly more complecated. To begin with the question of a state system of New China was of minor importance for Cheung Bin-ling. Cheung had developed his own concept of a state system. He declared frankly that in his view a republican system is "the smallest evil" which is to be necessarily resorted due to impossibility of fast implementation of a more perfect political project (Kalyuzhnaya, 1995). A little time later Cheung Bin-ling began to treat the republican system in a more critical way, up to its complete negation. He declared that the constitution serves only to concentrate the power in the same hands, the parliament has tendency to "gain power" and the president becomes equal to the monarch (it is certainly a consequence of Yuang Chi-kai's experience who having become the president was crowned afterwards). For the same reason the constitutional monarchy also did not appeal to Cheung Bin-ling. It the principle of national representation existing in all existing forms of government - a cornerstone of all western democracies that did not satisfy him (Murthy, 2011).

A complete justification of uselessness for China of the republican form of government with its representative system is stated in the article of Cheung Bin-ling "Is the representative system necessary?" (1908). The same work contained Cheung's new social project. In his opinion, the Chinese people which is a source of any right and any justice, is not yet ready for more active participation in public administration and lawmaking process. Cheung Bin-ling denied the idea of public representation as a whole. In his opinion, parliamentarism contradicts to principles of nationalism and national prosperity as "any law established from above serves the government, any law established from below serves people prosperity", and, therefore, the parliament will adopt laws, taking into consideration first of all their own interests (Murthy, 2011).

As a result of denial of the idea of national representation Cheung Bin-ling faced a very important and complicated question- what is the way to maintain a legislative process so that people's sovereignty would not 
suffer and the general will of the people would not be broken. According to Cheung Bin-ling's reasoning it turns out that the general will of the people was expressed long time ago and is contained in perfect establishments of old China. Since the most ancient times and up to now it has remained invariable, it is very easy to define, what leads to the following conclusions. Firstly, it is not required to express national will specially and, secondly, as the national will is invariable, the legislation should be the same. Cheung Bin-ling recognizes that national will should be the source of justice and, at the same time, absolutely denies the possibility of strong-willed creation of the legislation.

The idea of possibility of establishment of the perfect and invariable legislation is that basis on which the whole Cheung Bin-ling's social project (2013) is built. According to this project there are three highest dignitaries in the state- the president, the chief of the court and the trustee of educational institutions. Cheung Bin-ling considers such organization of the power a traditional Chinese principle. The president is elected by a universal voting from the most outstanding state dignitaries. Administrative matters, questions of the state defense and foreign policy are included into his management. The judicial system, at the head of which there is the chief of court, is urged to provide legislation observance, both from the people and from government officials, including the president who in case of breaking the law is brought to justice in accordance with general practice. The chief of the court and all other judges are elected directly by the same "legal estate" whose task is "formulation" of laws. At last, education authorities led by the trustee of educational institutions are urged to educate the people and to bring up their moral qualities. All educational institutions, except elementary schools and military colleges, are independent of the government.

The original concept of a state system could be hardly classified. The thinker recognized it as well: "If to call it the republic, it is the true republic and if to call it absolutism, it is an original absolutism". Cheung Bin-ling considered economically ideal the agrarian state living by a principle: "to bend the rich and strong, to assist the poor and weak". The state should limit the private capital in every possible way, forbid the combination of business and public service, carry out the principle of equality (the equation of land rights, equal legal liability, general compulsory education as means of involvement the people into a country governing). Cheung Bin-ling believed that all these principles correspond to the Chinese national culture and at the same time are close to socialism (Kalyuzhnaya, 1995).

\subsection{Cheung Bin-ling's Project of Achieving Nirvana}

Cheung Bin-ling recognized the world future earlier, than the present; the contrast between them was painful. His utopian project, by his own words, "is beyond rationalism"; it is called" the doctrine about cessation of births" (無生主義). The final aim of the development of society and the state is achievement of nirvana which is connected with Five disappearances (五無): 1) governments (無政府);2) settlements (無聚落); 3) mankind (無 人類); 4) all alive (無衆生); 5) physical Universe (無世界).

Cheung Bin-ng did not define the duration of each stage, but specified that the next period "cannot come accidentally", and the transition should be consecutive. Five disappearances can be reduced to three periods:

1. Disappearance of governments and constant settlements. It is explained by the fact that the governments provoke wars between races and people, aspiring to stand apart from each other. Therefore disappearance of governments should lead to elimination of wars and peace establishment in the whole world. The main reason of fight between people and social stratification is money, all trade will stop if property nationalization is carried out (共產), and money, as superfluous, “will be dumped into huge ditches". The existence of weapon pushes people to its use, i.e. to violence commission. Therefore the violence and capture will disappear, when guns and swords are broken. Absence of the government should lead to this consequence. However the element of the conflict is contained in family life as well: love between representatives of different genders generates jealousy and fight, while fathers and children depend on each other. That is why such relations cannot proceed. Communication of relatives should be based only on mutual compliance, only then envy and jealousy will disappear. All this will not lead to achievement of happiness: on the contrary, disappearance of happiness should destroy the evil.

However the government cannot be liquidated in one separate country for the governments of all countries are connected. Therefore, the governments should disappear in all the countries at the same time. For this purpose it is necessary to liquidate frontiers, to unify language and writing. However even these steps will not lead to a complete elimination of violence and war will proceed - just because constant settlements remain. The cause of it is that settlements are located in various geographical zones. As the inhabitants of cold countries with poor lands are compelled to spend many efforts to fertilize the soil, the find it simpler to take away fertile lands from neighbors with warm climate. And the cause will be not the government not liquidated by then, but natural 
conditions will be the reason for that. Therefore constant settlements should be abolished alongside with the governments. The population should conduct a nomadic way of life, migrating from areas with hot climate and corpulent land to cold lands with poor soils: people will annually change a profession and residence. It will be the only way possible to win quarrels and violence.

2. Neither government, nor state have their own nature (自性) for are created by people. Therefore disappearance of mankind will lead to disappearance of both mutual fight and conflicts for food, weapon and metal. Besides human race suppression will allow to get completely rid of the Ego and see clearly the essence of nirvana. However, to prevent the possibility for mankind to revive, it is necessary for all alive to disappear as in the course of evolution mankind, with their sorrows, passions and even the state quite can appear again.

3. During the last period all physical Universe - the real world should disappear. Cheung Ty-yang reasons from Buddhist positions: the existing Universe is a shelter for the living beings believing in its reality. However he compares the phenomenal world with a cataract on an eye -it is an illusion therefore it is necessary to destroy everything real so that the Universe which actually is emptiness will disappeared as well. On Five disappearances completion new revival will come, but this time it will happen in the incorporeal world of nirvana.

N.M. Kalyuzhnaya (1995) supported the idea of Japanese researcher Kondo Kuniyashu (近藤邦康, 1934) and agreed that this picture of "backward evolution" had developed under the influence of the Buddhistic views synthesized with anarchical theories and a traditional historical doctrine of circular motion. However it remained an episode in the intellectual biography of Cheung Ty-yang. It is characteristic that he did not connect the ideal with the Great Unification according to Kang Yu-wei (Kalyuzhnaya, 1995).

\section{Discussions}

While the works on conservative thought of the Chinese intellectuals of Kang Yu wei's group appeared in western sinology in the 1960th the works of Cheung Bin-ling have attracted the attention of sinologists recently, and only one his original work is translated into English. The most fundamental work devoted to him, was issued in 2011 - it was a monograph by V. Murthy. The first collection of Cheung Bin-ling's works was issued in a European language in Russia in 2013 (12 articles of the period of 1894-1913), and became the result of almost half a century work of N.M. Kalyuzhnaya.

\section{Conclusion}

Kang Yu-wei's conservatism became evident during the preparation and carrying out national revolution in China, besides it was mostly superficial and was reduced to preservation of national culture during a colonial era. Kang Bin-ling defended consequently the theory of a superiority of the Chinese traditional culture over the western one. Denying western institutions of people's representation, he believed that "the general will of the people" was expressed in public establishments of traditional China, and remains invariable since the most ancient times.

\section{Acknowledgments}

The work is performed according to the Russian Government Program of Competitive Growth of Kazan Federal University.

\section{References}

Chang, H. (1987). Chinese Intellectuals in Crisis: Search for Order and Meaning (1890 - 1911). Berkeley, CA: Univ. of California Press.

Cheung, B.-L. (2013). Selected works (1894-1913), Moscow: Sience, Easten Literatura. (Izbranniye proizvedeniya (1869-1936) Moscva: Nauka, Vostochnaya literature.

Hsiao, K.-C. (1975). Modern China and NewWorld. K'ang Yu-wei, Reformer and Utopian, 1858-1927, Seattle, WA - London, Eng.: Univ. of Washington Press.

Kalyuzhnaya, N. M. (1995). Tradition and revolution. Cheung Bin-ling (1869-1936)-chinese thinker and politician of a New time, Moscow: Press Administration of Moscow region. (Tradiciya e revolyuciya. Cheung Bin-ling (1869 - 1936) - kitaiskyi mislitel e politicheslyi deyatel Novogo vremeni, Moscva: Izdatelskoye upravleniye pravitelstva Moscovskoi oblasti.

Kang, Y.-W. (2007). Kang Youwei quan ji (Vol. 12), Beijing: Zhongguo renmin daxue chubanshe.

Laitinen, K. (1990). Chinese Nationalism in the Late Qing Dynasty: Zhang Binglin as an Anti-Manchu Propagandist. London, Eng.: Curzon Press. 
Levenson, J. R. (1958). Confucian China and its Modern Fate. Berkeley, CA: Univ. of California Press.

Martinov D. E. (2008). Foreign missionaries in China XIX-XX centuries: specifics of activity (on the example of Shandung province) Bulletin of the Tatarstan State Humanitarian-Pedagodical University. (Inostranniye missioneri v Kitaye XIX-XX centuries: cpecifika deyatelnosti (na primere provinciyi Shandun). Vestnik Tatarscogo gocudarstvennogo gumanitarno-pedagogicheskogo universiteta, 3(40-45), 2074-0239.

Martinov, D. E. (2010). Kang-Yu-wei: Bybliography, Kazan: Kazan un-ty press. (Kan-Yu-vei: Zsizneopisaniye, Kazan: Izdatelstvo Kazanskogo Universiteta).

Murthy, V. (2011). The Political Philosophy of Zhang Taiyan. The Resistance of Consciousness, Leiden, Nl.: Brill. http://dx.doi.org/10.1163/ej.9789004203877.i-268

\section{Copyrights}

Copyright for this article is retained by the author(s), with first publication rights granted to the journal.

This is an open-access article distributed under the terms and conditions of the Creative Commons Attribution license (http://creativecommons.org/licenses/by/3.0/). 